\title{
Appendicular Abscess in General Surgery at the Bocar Sidi Sall University Hospital in Kati
}

\author{
Abdoulaye Diarra ${ }^{1 *}$, Koniba Keita ${ }^{1}$, Amadou Traoré ${ }^{2}$, Assitan Koné ${ }^{1}$, Idrissa Tounkara ${ }^{2}$, \\ Issa Traore1, Souleymane Thiam², Fadima K. Tall ${ }^{3}$, Daouda Diallo3 ${ }^{3}$, Madiassa Konate ${ }^{2}$, \\ Aboubacar Koné1, Deborah Sanra Sanogo ${ }^{4}$, Ismaël Konare1, Alhassane Traoré2, Adégné Togo² \\ ${ }^{1}$ Department of General Surgery, CHU of Kati, Kati, Mali \\ ${ }^{2}$ General Surgery Department, CHU Gabriel Touré, Bamako, Mali \\ ${ }^{3}$ Department of Anesthesia and Resuscitation, CHU of Kati, Kati, Mali \\ ${ }^{4}$ Gastroenterology Department, Point G Hospital, Bamako, Mali \\ Email: *abdoulayeg2004@yahoo.fr
}

How to cite this paper: Diarra, A., Keita, K., Traoré, A., Koné, A., Tounkara, I., Traore, I., Thiam, S., Tall, F.K., Diallo, D., Konate, M., Koné, A., Sanogo, D.S., Konare, I., Traoré, A. and Togo, A. (2020) Appendicular Abscess in General Surgery at the Bocar Sidi Sall University Hospital in Kati. Surgical Science, $11,479-485$

https://doi.org/10.4236/ss.2020.1112050

Received: November 16, 2020

Accepted: December 25, 2020

Published: December 28, 2020

Copyright (c) 2020 by author(s) and Scientific Research Publishing Inc. This work is licensed under the Creative Commons Attribution-NonCommercial International License (CC BY-NC 4.0). http://creativecommons.org/licenses/by-nc/4.0/ (c) (i) (s) Open Access

\begin{abstract}
Introduction: Appendicular abscess is a progressive complication of acute appendicitis in which the spread of infection is contained by the greater omentum and the slender loops resulting in the formation of a true septate abscess of the large peritoneal cavity. Materials and Methods: This was a retrospective study from January 2010 to December 2019 carried out at the Bocar Sidi Sall University Hospital in Kati (CHU BSS in Kati) in general surgery. It concerned all patients operated on for appendicular abscess in the department. Results: 75 cases of appendicular abscess were collected, which represented $5.76 \%$ of surgical emergencies and $25 \%$ of acute appendicitis. The average age of the patients was 29 years. The male sex represented $67 \%$ of our patients with a sex ratio of 2 . The average consultation time was 5 days. Abdominal pain was noted in all patients. It was localized in the right iliac fossa in $80 \%(n=60)$ and diffuse in $2.7 \%$ of cases $(n=2)$. It was accompanied by nausea and vomiting in $93 \%$ of cases $(n=70)$, urinary disorders in $20 \%$ ( $n$ $=15)$, fever in $94 \%(n=71)$, cessation of materials and gas in $1.33 \%(n=1)$. Abdominal ultrasound was performed in $86 \%(n=65)$. It made it possible to suggest a peri-appendicular effusion. Biological examination revealed a neutrophilic hyperleukocytosis greater than $20,000 / \mathrm{mm}^{3}$ in 47 patients, or $63 \%$. All the patients were operated on by laparotomy (Marc Burney or midline subumbilical) under general anesthesia. The length of hospitalization was 6 days. We have not recorded any deaths. Morbidity was $8 \%(n=6)$ represented by parietal suppuration. The postoperative course was straightforward in $92 \%$ of cases $(n=69)$. Conclusion: Appendicular abscess is a frequent medico-surgical emergency, the prognosis of which depends greatly on early diagnosis and
\end{abstract}


adequate and immediate management.

\section{Keywords}

Appendicular Abscess, Surgery, Kati, Mali

\section{Introduction}

Appendicular abscess is a progressive complication of appendicular perforation, in which the spread of infection is contained by the greater omentum and the slender loops, resulting in the formation of a true septate abscess of the large peritoneal cavity [1]. It constitutes a medico-surgical emergency and accounts for $10 \%$ of acute appendicitis in adults in Africa [2]. The diagnosis is purely clinical, but if in doubt ultrasound is the first line examination. This ultrasound has a sensitivity of $80 \%$ for diagnosis, and can provide additional information on the topography in case of doubtful diagnosis [2]. This is an exam that is often operator-dependent and difficult when there is too much intestinal gas.

Any appendicular abscess diagnosed must be operated on as soon as possible in order to remove the infectious focus and thus prevent its spread into the large peritoneal cavity. The risk of contamination of the peritoneal cavity in the form of a three-stage peritonitis and digestive fistulas after attempts at appendectomies have made the practice of extra-peritoneal drainage if possible and a delayed appendectomy accepted as therapeutic [3]. Others are for appendectomy and drainage at the same time of operation [4]. Emergency drainage can be done by interventional radiology or by laparotomy associated with appropriate antibiotic therapy [5]. We did not have data concerning the management of this pathology in our department, which motivated us to initiate this work with the objectives of determining the frequency of appendicular abscesses, to describe the diagnostic and therapeutic aspects and to analyze postoperative treatment.

\section{Material and Methods}

This was a retrospective study from January 2010 to December 2019 carried out at the CHU Bocar Sidi Sall in Kati in general surgery. It concerned all patients operated on for appendicular abscess in the department. Generalized appendicular peritonitis and acute appendicitis were not included in this study. We did an exhaustive recruitment of all patients operated on for appendicular abscess who met the inclusion criteria. Our work support was based on the medical files of the patients, all the registers of outpatient consultations, operative reports and hospitalization. The parameters studied were socio-demographic data, clinical and paraclinical, therapeutic data and the course of the pathology. The pathological data were also reviewed. Data analysis was performed using Excel and Epi info $6.0 \mathrm{fr}$ software. The statistical test used was $\mathrm{Chi}^{2}$ with a significance level $\mathrm{p}<$ 0.05 . 


\section{Results}

During this study period 1300 patients were operated on urgently, including 300 cases of acute appendicitis, including 75 cases of appendicular abscess, i.e. 5.77\% of surgical emergencies and $25 \%$ of acute appendicitis. The mean age of the patients was $29 \pm 14.04$ years with extremes of 15 and 70 years. Figure 1 shows the different age groups. The male sex represented $67 \%$ of our patients versus $33 \%$ of the female sex and the sex ratio was 2 . The mean consultation time was $5 \pm 3.1$ days (range: 2 and 60 days). Abdominal pain was noted in all patients with a sudden onset in $45.95 \%$ and progressive in $54.05 \%$. It was localized in the right iliac fossa in $80 \%(\mathrm{n}=60)$ and diffuse in $2.7 \%(\mathrm{n}=2)$. It was accompanied by nausea and vomiting in $93 \%(n=70)$, urinary disorders in $20 \%$ of cases $(n=15)$, fever in $94 \%$ of cases $(n=71)$, stopping of materials and gas in $1.33 \%$ of cases ( $\mathrm{n}$ $=1)$. Table 1 summarizes the functional signs. On physical examination there was a localized contracture in the right iliac fossa in $90 \%$ of cases. The physical signs are grouped together in Table 2. Abdominal ultrasound was performed in $86 \%$ of cases $(n=65)$. She suggested a peri-appendicular effusion. Biological

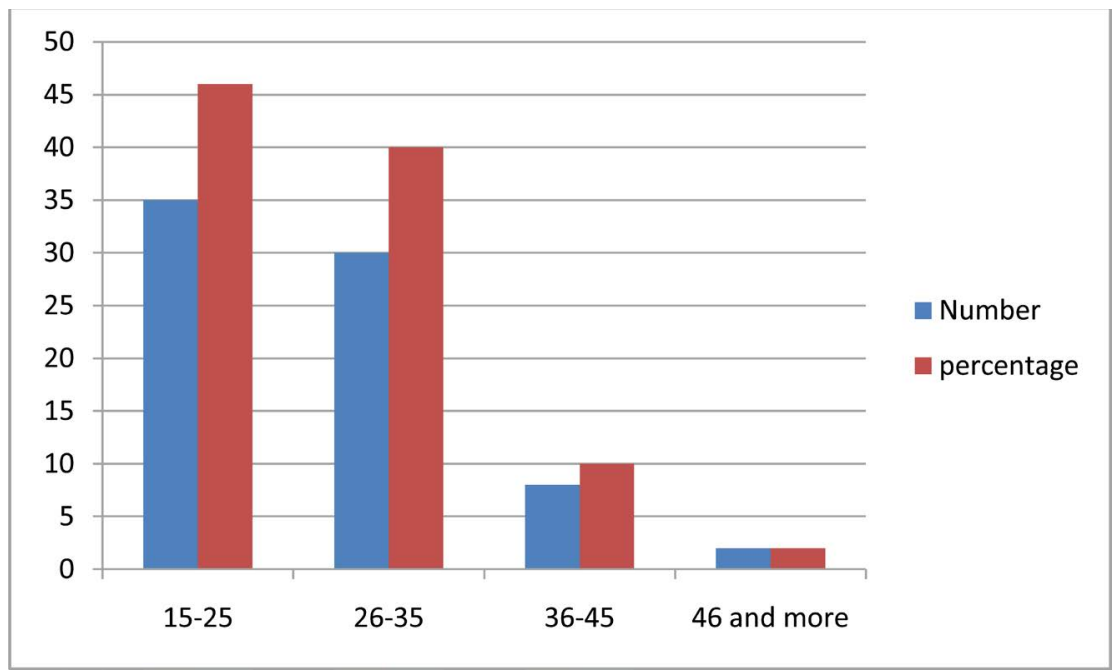

Figure 1. Age group in years.

Table 1. Functional signs.

\begin{tabular}{ccc}
\hline Functional signs & Number & Percentage \\
\hline Pain & 75 & 100 \\
Stop of materials and gases & 1 & 1,33 \\
Urinary disorders & 15 & 20 \\
constipation & 15 & 20 \\
bloat & 3 & 4 \\
diarrhea & 3 & 4 \\
Nausea and vomiting & 70 & 93 \\
Rumbling of the right iliac fossa & 5 & $6,6 \%$ \\
\hline
\end{tabular}


examination revealed a neutrophilic hyperleukocytosis greater than $20,000 / \mathrm{mm}^{3}$ in 47 patients, (63\% of cases). All patients were operated on by laparotomy under general anesthesia. The first approach was the Marc Burney incision in 93\% of cases $(n=70)$ and a midline subumbilical incision in $7 \%$ of cases $(n=5)$.

The appendix was laterocecal in $90 \%$ of cases $(n=68)$, retro cecal in $7 \%$ of cases $(n=5)$, and mesoceliac in $3 \%(n=2)$. Table 3 summarizes the amount of pus aspirated. Macroscopically, the appendix was perforated in $80 \%$ of cases $(\mathrm{n}=$ $60)$, gangrenous in $13.3 \%$ of cases $(n=10)$, phlegmonous in $6.6 \%$ of cases $(n=$ 5). Figure 2 shows a necrotic appendix before appendectomy and Figure 3 a surgical specimen from a necrotic appendix.

We performed appendectomy with burial of the appendicular stump in $73 \%$ of cases $(n=55)$, associated with drainage of the right iliac fossa with a Delbet drain; appendectomy without burial and drainage in $24 \%$ of cases $(n=18)$,

Table 2. Physical signs.

\begin{tabular}{ccc}
\hline Physical signs & Number & Percentage \\
\hline Pain in Douglace's cul de sac & 75 & 100 \\
Right iliac fossa defense & 7 & 9 \\
Contracture of the right iliac fossa & 68 & 90 \\
Arch of the right iliac fossa & 20 & 26 \\
\hline
\end{tabular}

Table 3. Distribution according to the amount of pus aspirated.

\begin{tabular}{ccc}
\hline Amount of pus in milliliter & Number & Percentage \\
\hline$<20$ & 3 & $4 \%$ \\
$30-50$ & 10 & $13 \%$ \\
$60-90$ & 60 & $80 \%$ \\
$>100$ & 2 & $3 \%$ \\
\hline
\end{tabular}

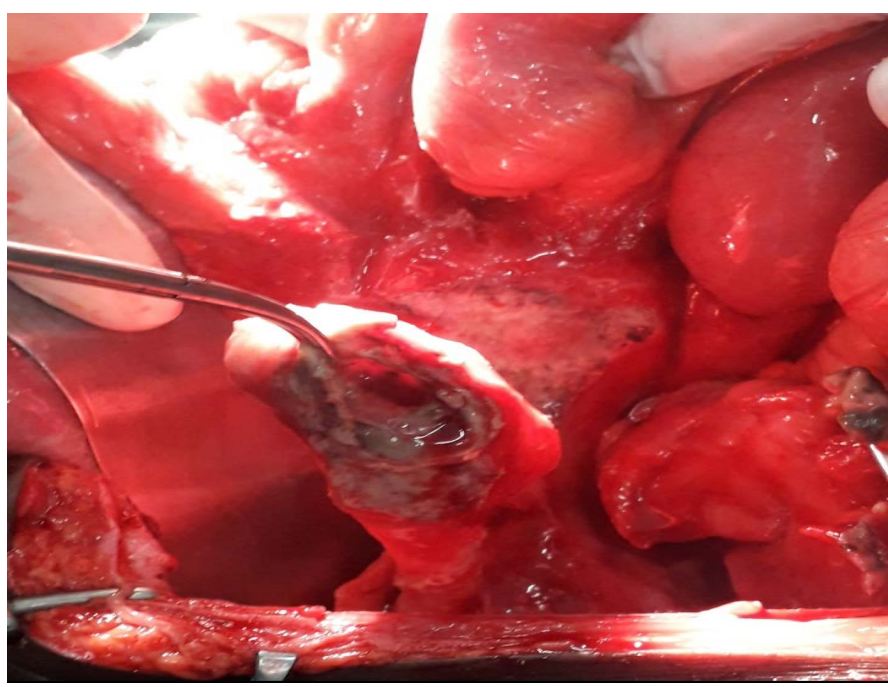

Figure 2. Appendicular perforation abscess. 


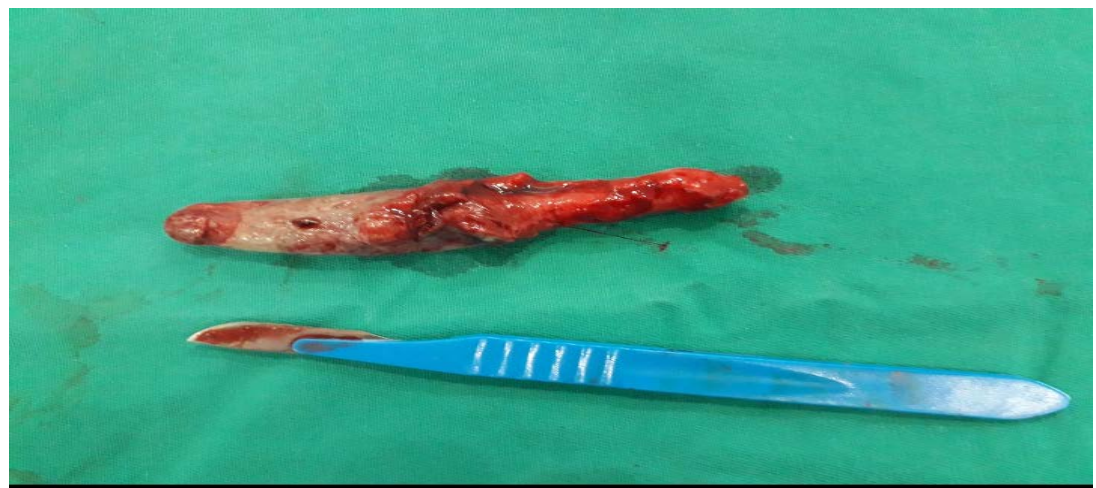

Figure 3. Appendectomy patch for appendicular abscess.

drainage alone (delayed appendectomy) in $3 \%$ of cases $(\mathrm{n}=2)$. The anatomopathological study was carried out on all surgical specimens, thus confirming the diagnosis of appendicular abscess. On cytobacteriological examination of the pus, the most found germs were Escherichia coli in 51\%, Klebsiella oxytoca in 16\%, Klebsiella pneumoniea 13\%, Enterobacter cloacoe 11\% The germs found were $100 \%$ sensitive to imipenem. The length of hospitalization was 6 days (range: 2 and 17 days).

We have not recorded any deaths. Morbidity was $8 \%(\mathrm{n}=6)$ represented by parietal suppuration. The postoperative course was straightforward in $92 \%$ of cases $(n=69)$.

\section{Discussion}

An appendicular abscess is a significant complication of acute appendicitis. It accounts for $10 \%$ of acute appendicitis in adults in Africa [2], versus $50 \%$ in young children [1]. In our series, it represented $25 \%$ of acute appendicitis. Acute appendicitis being an affection of the young subject, appendicular abscess is also it, the same observations were made in the Cameroonian and Nigerian series. Sex does not represent a risk factor [6], the sex ratio of our series is identical to that of the Nigerian and Cameroonian authors [2] [7].

The time to consultation is a determining factor in the prognosis of appendicitis, and therefore in the occurrence of a probable abscess [8] [9]. We observed a real delay in the consultation after the onset of symptoms in our study with an average duration of 5 days; which is the basis of the constitution of the abscess itself. The same is true for Hussain in Saudi Arabia who reported an average consultation time of 6 days [10].

The diagnosis of the abscess is usually clinical. Pain in the right iliac fossa and fever are the most constant signs in our study and that of Cameroonian and Saudi authors [2] [10]. This violent pain is generally non-variable (right iliac fossa) [5] [11].

The parietal defense of the right iliac fossa due to peritoneal irritation as well as the wheelbase are signs that strongly support appendicular abscess [5].

Ultrasound with a diagnostic sensitivity of $80 \%$ can provide additional infor- 
mation on the topography in case of doubtful diagnosis [2]. This is an exam that is often operator-dependent and difficult when there is too much intestinal gas. Polynuclear neutrophilic hyperleukocytosis is constant, in our study it was greater than $20,000 / \mathrm{mm}^{3}$ in 47 patients, or $63 \%$ of cases. Any appendicular abscess diagnosed must be operated on as soon as possible in order to remove the infectious focus and thus prevent its distribution into the large peritoneal cavity.

Laparoscopy is recommended for its advantages over the open approach, however it is not recommended by Bittner R and Frazée RC in very advanced cases [6] [8].

Mac Burney's approach is the most popular in terms of its elective and aesthetic character. It was performed in $85.71 \%$ of cases during our study. For the other patients, the wide midline approach was performed because of signs suggestive of generalized peritonitis in $14.29 \%$ of cases. These different approaches were guided by the clinic and often the intraoperative findings.

The therapeutic strategy to adopt is controversial. Previously, authors suggested drainage of the abscess and the appendectomy was postponed three to six months after [3] in order to avoid intraoperative complications. Others are for appendectomy and drainage at the same time of operation [4].

Appendectomy with drainage of the abscess is the treatment of choice with a low morbidity rate and shorter hospital stay [12]. The burial of the appendicular stump will depend on local conditions, in other words the degree of inflammation of the cecal wall.

Some authors systematically practice appendicular burying, others on the contrary condemn this practice because, according to them, the inflammation of the appendicular stump promotes perforation of the lower fundus cecal [13].

The morbidity in our series of $14.3 \%$ is higher than those of the Cameroonian [2] and Italian [14] series, this could be related to the size of our sample. Mortality is mainly a function of the degree of septicity of the cavity, the time taken to take charge and the associated defects. We have not recorded any deaths.

\section{Conclusion}

Appendicular abscess is a frequent medico-surgical emergency, the prognosis of which depends greatly on early diagnosis and adequate and immediate management.

\section{Conflicts of Interest}

The authors declare no conflicts of interest regarding the publication of this paper.

\section{References}

[1] Garcia, S., Heloury, Y. and Plattner, V. (1990) Appendicite aigue et péritonite: Chirurgie digestive de l'enfant. Ed. Douin, Paris, 6.

[2] Guifo, M.L., Takongmo, S. and Fokou, M. (2010) Abcès appendiculaire: Analyse de 
19 cas traités au CHU de Yaoundé et Déductions pratiques. Pan African Medical Journal, 5, 236-239.

[3] Menegaux, G. and Menegaux, J.C. (1965) Manuel de pathologie chirurgical. Masson et Cie Editeurs, Paris.

[4] Eriksson, S. and Styrud, J. (1998) Interval Appendicectomy: A Retrospective Study. European Journal of Surgery, 164, 771-774. https://doi.org/10.1080/110241598750005417

[5] Valayer, J., et al. (1989) Appendicite et péritonite appendiculaire de l'enfant. Encyclopédie Medicale de Chirurgie (Paris), 146, 10-19.

[6] Reinhard, B. (2006) Laparoscopic Surgery-15 Years after Clinical Introduction. World Journal of Surgery, 30, 1190-203. https://doi.org/10.1007/s00268-005-0644-2

[7] Okafor, P.I.S., Okafor, J.C. and Chianakwana, G.U. (2003) Management of Appendiceal Masses in Peripheral Hospital in Nigeria: Review of Thirty Cases. World Journal of Surgery, 27, 800-803. https://doi.org/10.1007/s00268-003-6891-1

[8] Frazee, R.C., Roberts, J.W., Symmonds, R.E., Snyder, S.K., Hendricks, J.C., Smith, R.W., Custer3rd, M.D. and Harrison, J.B. (1994) A Prospective Randomized Trial Comparing Open Versus Laparoscopic Appendectomy. Annals of Surgery, 219, 725-728. https://doi.org/10.1097/00000658-199406000-00017

[9] Farthouat, P., Fall, O., Gougbemy; M.O., Sow, A. and Millo, A. (2005) Appendicectomie en milieu tropical: Etude prospective à l'Hopital principal de Dakar. Medecine Tropicale, 65, 549-553.

[10] Hussain et al. (2011) Gestion des abcès appendiculaires: Département de Chirurgie King Saud Medical City, Riyad au Royaume uni d'Arabie Saoudite. Thèse de Médecine, 4.

[11] Mutter, D. and Marescaux, J. (2013) Appendicites aigues, chirurgie A, Hôpital civil. Strasbourg. Digestive Diseases, 31, 76-82.

[12] Brocoq, P., Poilleux, F. and Charbrut, R. (1925) Appendicite aigue vue tardivement. Traité des urgences en Chirurgie Tome 1, Masson, 588-590.

[13] Paulin, F. (1987) Les aspects épidémiologiques, cliniques et thérapeutiques de l'appendicite de l'enfant de zéro à dix-sept ans au CHU Yalgado Ouedraogo Burkina Faso. Thèse de Médecine, 36.

[14] Chir, M. (1997) Le rôle de la chirurgie dans le traitement de l'abcès appendiculaire. Annalede Chirurgie, 52, 577-581. 